\title{
Spectrum of Severe Sepsis in Critically Ill Adult Patients of Bangladesh: A Prospective Observational study
}

\author{
Fatema Ahmed ${ }^{1}$, Mohammad Omar Faruq ${ }^{2}$, A S M Areef Ahsan ${ }^{3}$, Kaniz Fatema ${ }^{4}$, Mohammad Shah Zaman ${ }^{5}$
}

\begin{abstract}
:
Background: Severe sepsis is the leading cause to Intensive Care Unit (ICU) admission. However few studies have described the primary source of the severe sepsis in Bangladesh.

Objectives: General objective was to identify the clinical presentation of infection in severe sepsis patients \& specific objective was to determine the primary and commonest source of infection in severe sepsis.

Methods: This was a prospective cross sectional study done over seven months period starting from June 1, 2012 to December 31, 2012 in the dept. of Critical Care Medicine of BIRDEM General Hospital. All ICU admissions from the emergency department, medical and surgical in patients who were screened daily for the presence of severe sepsis or septic shock using a screening tool, which included definitions of sepsis and organ dysfunctions. All consecutive patients with severe sepsis were enrolled as study subjects.

Results: A total of 228 patients were admitted in ICU and among them, 95 patients of severe sepsis were included. The mean age of the patients was 59.56 years \& male to female ratio being 3:2. Ninety two (92\%) patients had any kind of comorbidity. Commonest comorbidity was diabetes mellitus (77\%). Respiratory, renal dysfunction, and cardiovascular, were the most frequent organ dysfunctions $(87 \%, 64 \%, 58 \%$, respectively). In severesepsis patients single organ dysfunction was $30 \%$, double organ dysfunction was also $30 \%$ \& triple organ dysfunction was $35 \%$ of patients. The most common primary source of infection were the respiratory system $70 \%$, followed by urinary tract $11 \%$, intravascular catheter related infection $7 \%$ and abdomen $5 \%$.
\end{abstract}

Conclusion: Severe sepsis is a significant \& common health problem in ICU Patients of Bangladesh. An understanding of the primary sources of severe sepsis is vital for treatment and these information will allow us to make preventive strategy for severe sepsis.

Key words: Sepsis, severe sepsis, primary sources of severe sepsis, organ dysfunction.

\section{Introduction :}

Severe sepsis is a leading cause of Intensive Care Unit (ICU) admission. This study was done primarily to identify the primary sources of infection and specifically to determine the commonest sources of infection in severe sepsis patients.

1. Dr. Fatema Ahmed MD (Critical Care Medicine), FCPS (Med), Jr. Consultant, Dept. of Critical Care Medicine, BIRDEM General Hospital

2. Prof. Mohammad Omar Faruq, MD, FACEP, FACP, FCPS, FCCM, Professor, Dept. of Critical Care Medicine, BIRDEM General Hospital,

3. Dr. ASM Areef Ahsan, FCPS (Medicine), MD (Chest), MD (CCM), Associate Professor \& Head, Dept. of Critical Care Medicine, BIRDEM General Hospital.

4. Dr. Kaniz Fatema, FCPS (Medicine), MD (CCM), Assistant Professor, Dept. of Critical Care Medicine, BIRDEM General Hospital, Dhaka

5. Dr. Md. Shah Zaman. DDV, MCPS (Dermatology), Consultant, Dept of Dermatology, Uttara Crescent Hospital, Dhaka

\section{Corresponding Author:}

Dr. Fatema Ahmed,

Junior Consultant, Dept. of Critical Care Medicine,

BIRDEM General Hospital, Shahbag, Dhaka-1000, Bangladesh

E-mail: fatema.ahmed77@ymail.com
Sepsis is a systemic, deleterious host response to infection and leads to severe sepsis (acute organ dysfunction secondary to documented or suspected infection) and septic shock (severe sepsis plus hypotension not reversed with fluid resuscitation $)^{1}$.

Severe sepsis accounts for 1 in 5 admissions to intensive care units (ICUs) and is a leading cause of death in non-cardiac French $\mathrm{ICU}^{2,3}$.

Treatment of severe sepsis and septic shock is expensive, frequently fatal condition and affecting millions of people around the world each year, killing one in four cases (and often more), and incidence is increasing ${ }^{4}$. Early identification of sources of infection and prompt appropriate therapy guided by source control influences the outcome. Few studies have described the primary sources of severe sepsis in Bangladesh and for this reason this study is relevant for our population.

\section{Materials and Methods:}

This cross-sectional study was done medical ICU of BIRDEM General Hospital from June 1, 2012 to Dec 31, 2012 during which total 228 patients were admitted. During the study period all consecutive patients in the ICU with severe sepsis were enrolled as study subjects by using the Surviving Sepsis Campaign (SSC) ${ }^{1}$ definitions. Patients who were $\geq 18$ years, ICU stay longer than 12 hours from the time of diagnosis of severe sepsis were included in the study. 
Bangladesh Crit Care J September 2015; 3 (2): 45-48

Patients having repeated episodes of severe sepsis during the current admission in ICU, only the first episode longer than 12 hours from time of diagnosis were included in the study. Patients who were below 18 years and had ICU stay shorter than 12 hours from the time diagnosis of severe sepsis, pregnant patient, patient with acute myocardial infarction or shock due to noninfectious causes, patients with end-stage renal diseases (ESRD) excluding renal dysfunction from organ dysfunction criteria and body fluid of any patient shows more than one micro-organism were excluded from the study. Investigations like chest $\mathrm{x}$-ray, complete blood count, Blood sugar, liver function test (Bilirubin, ALT), renal function test (blood urea, serum creatinine), coagulation profile, serum lactate and $A B G$ were sent to BIRDEM lab from patients suspected to have sepsis. Primary source of infection and organ dysfunction were identified and appropriate cultures were done.

Analysis was performed. Continuous variables were expressed as mean \pm standard deviation (SD). Categorical or qualitative data were expressed as frequency with corresponding percentages. Level of significance was set at $5 \%$ or 0.05 and $\mathrm{p}<0.05$ was considered significant. Statistical analysis was performed using SPSS (Statistical Packages for Social Sciences) software version 18.

\section{Results:}

Total number of study patients was 95 . It was $41 \%$ of total ICU admissions (228) during the study period. Males were $57(60 \%)$ and females were $38(40 \%)$. Mean age of the study population was 59.56 $( \pm 14.3)$ years (Table I)

Table I: Age distribution of sever sepsis patients $(\mathrm{N}=95)$

\begin{tabular}{lcc}
\hline Age group & Frequency & Percent \\
\hline$\leq 40$ & 12 & 12.6 \\
$41-50$ & 11 & 11.6 \\
$51-60$ & 23 & 24.2 \\
$61-70$ & 27 & 28.4 \\
$71-80$ & 16 & 16.8 \\
$\geq 81$ & 6 & 6.3 \\
\hline
\end{tabular}

Table II: Different types of comorbidities in study population $(\mathrm{N}=95)$

\begin{tabular}{lcc}
\hline Co-morbidity & Frequency & Percent \\
\hline Diabetes Mellitus & 73 & 76.8 \\
Ischemic heart disease & 32 & 33.7 \\
Hypertension & 32 & 33.7 \\
Chronic kidney disease & 29 & 30.5 \\
Cerebro-vascular disease & 12 & 12.6 \\
End stage renal disease & 6 & 6.3 \\
Chronic obstructive pulmonary disease & 5 & 5.3 \\
Asthma & 3 & 3.2 \\
Known Malignancy & 2 & 2.1 \\
Immunosuppression & 2 & 2.1 \\
\hline
\end{tabular}

Among the study subjects, common co-morbidities were diabetes $(73,76.8 \%)$, HTN $(32,33.7 \%)$, ischemic heart disease (32, 33.7\%) and chronic kidney disease (29, 30.5\%). Other comorbid conditions are shown in Table II.

Table III described the pattern of organ dysfunction among the study subject.

Table III: Organdysfunction $(\mathrm{N}=95)$

\begin{tabular}{lcc}
\hline Organ dysfunction & Frequency & Percent \\
\hline Respiratory & 83 & 87 \\
Renal & 61 & 64.2 \\
Cardiovascular & 55 & 58 \\
Liver & 8 & 8.4 \\
Coagulation system & 10 & 10.5 \\
Thrombocytopenia* & 33 & 34 \\
\hline
\end{tabular}

(*platelet <100000/cumm.)

Table IV describe different source of infection in our study subject. The most common source of infection was the respiratory system $(66,70 \%)$, followed by urinary tract (11, $11 \%$ ). Intravascular catheter related infection was responsible in $7(7.4 \%)$ cases. Other less common sources are shown in table IV.

Table IV: Primary source of severe sepsis $(\mathrm{N}=95)$

\begin{tabular}{lccc}
\hline Primary sources of sepsis & Frequency & Percent & P value \\
\hline Pneumonia & 66 & 69.5 & .005 \\
UTI & 11 & 11.6 & NS* \\
Abdomen other than UTI & 4 & 4.2 & NS \\
CNS Infection & 4 & 4.2 & NS \\
Soft tissue/ skin & 2 & 2.1 & NS \\
Intravascular catheter & 7 & 7.4 & NS \\
Infective-endocarditis & 1 & 1.1 & NS \\
\hline
\end{tabular}

*NS $=$ not significant

Pneumonia was the predominant source of infection in my study $(\mathrm{p}<.005$.) The difference between the proportion of pneumonia as a source of sepsis and other source of sepsis apart from pneumonia which is significant.

Tracheal aspirate culture, blood culture, urine and culture from specific body fluids (like CSF) depending on the site of infection were sent.

Table V: Pattern of micro- organism in tracheal aspirate Culture

\begin{tabular}{lcc}
\hline Organism in tracheal culture & Frequency & Percent \\
\hline Pseudomonas aeruginosa & 10 & 12 \\
Acinetobacter & 52 & 64 \\
AFB & 1 & 2 \\
Klebsiella & 5 & 6 \\
Candida & 4 & 5 \\
No growth & 9 & 11 \\
\hline Gram negative organism is & predominant cause of lung \\
infection like pneumonia. & &
\end{tabular}


Table VI: Micro-organism in blood culture

\begin{tabular}{lcc}
\hline Blood C/S & Frequency & Percentage \\
\hline No growth & 81 & 85.3 \\
Staphylococcus aureus & 3 & 3.2 \\
Candida & 2 & 2.1 \\
Acinetobacter & 3 & 3.2 \\
pseudomonas aeruginosa & 5 & 5.3 \\
Ecoli & 1 & 1.1 \\
\hline
\end{tabular}

In blood culture, Gram negative bacteria were 9 (10\%), while gram positive bacteria were

accountedfor3 (3\%), fungus was present $2(2 \%)$ and culture negative was $81(85.3 \%)$.

In urine culture, predominant organism Ecoli 4(4\%), pseudomonas $3(3 \%)$, candida $4(4 \%)$ and culture negative was $84(88 \%)$.

\section{Discussion :}

As per result 95 out of 228 patients fulfilled criteria of severe sepsis criteria during the study period. So $41 \%$ of all admitted patients were suffering from severe sepsis. The mean \& SD of age in this study were $59.56( \pm 14.3)$ years. Commonest age range was $61-70(28 \%)$ indicating elderly were more prone to developed severe sepsis.

Guidet et $\mathrm{al}^{3}$. compared non-severe sepsis patients with severe sepsis patients and found that severe sepsis patients were significantly older and had male predominance. In this study $60 \%(n=57)$ were male \& $40 \%(n=38)$ were female.

In this study diabetes mellitus (DM) was the most common (77\%) comorbidity. Angus et al. described in epidemiology of severe sepsis in the United States: analysis of incidence, outcome, and associated costs of care noticed that certain comorbid conditions such as diabetes mellitus, chronic liver diseases, HIV, and cancer have been suggested to increase the risk of developing sepsis ${ }^{4}$.

Respiratory, renal and circulatory dysfunctions were the most frequent organ dysfunctions $(87 \%, 64 \%$ and $58 \%$ respectively) in this study.

Engel et al. ${ }^{5}$ conducted epidemiology of sepsis in Germany and found that respiratory and renal dysfunction were the most frequent organ dysfunctions $(52 \%$ and $42.2 \%$, respectively) and the most frequent sites of infection were the respiratory tract $(62.9 \%)$ and the abdomen $(25.3 \%)$.

Greg et al. ${ }^{6}$ found the organs that failed most frequently in patients with sepsis were the lungs (18\%) and the kidneys (15\%).

This study showed single organ dysfunction was found in $30 \%$ of study population, double organ dysfunction was also $30 \%$ \& triple organ dysfunction was 35\%. Organ failure had a cumulative effect on mortality. Derek et al. ${ }^{7}$ found acute organ dysfunction single organ dysfunction $73.6 \%$, two organ dysfunction $20.7 \%$, three organ dysfunction $4.7 \%$ and three organ involvement associated with $64 \%$ mortality.

Acinetobacter sp. was the predominant organism isolated from tracheal aspirate culture $(64 \%)$ followed by Pseudomonas sp. (12\%) and Klebsialla sp. (6\%),Candida albicans (5\%). Fernando Zanonetal. ${ }^{8}$ found common pathogens for sepsis are Gram negative 53.2\% and Gram positive $30.4 \%$.

The most common primary source of infection in this study was the respiratory system $69.5 \%(n=66)$, followed by urinary tract $11.4 \%(\mathrm{n}=11)$, intravascular catheter related infection $7.4 \%(\mathrm{n}=7)$, abdomen $4.6 \%(\mathrm{n}=4)$, meningo-encephalitis $4.2 \% \quad(n=4)$, skin and soft tissue $2.1 \%$ and infective endocarditis $1 \%$.

Table VII shows comparison among primary sources of severe sepsis with Bangladeshi study. It is found that respiratory system is the commonest in all the study.

Table VII: Primary sources of severe sepsis in different study

\begin{tabular}{|c|c|c|c|c|c|c|c|}
\hline $\begin{array}{l}\text { Primary } \\
\text { Source of study infection }\end{array}$ & $\begin{array}{l}\text { Our } \\
\text { Study }\end{array}$ & $\begin{array}{c}\text { Brazil } \\
{ }^{9} \text { Kauss } \\
2010\end{array}$ & $\begin{array}{c}\text { Asia } \\
{ }^{10}(\mathrm{MOSAICS}) \\
2011\end{array}$ & $\begin{array}{c}\text { Spain } \\
{ }^{11} \text { Ricard } \\
2011\end{array}$ & $\begin{array}{c}\text { USA, Europe } \\
{ }^{12} \text { Mitchell } \\
2010\end{array}$ & $\begin{array}{c}\text { Germany } \\
{ }^{5} \text { Engel } \\
2007\end{array}$ & $\begin{array}{c}\text { Bangladesh } \\
{ }^{13} \text { Faruq } \\
2013\end{array}$ \\
\hline Pneumonia/lung & $69.5 \%$ & $66.5 \%$ & $37.4 \%$ & $38.5 \%$ & $44.4 \%$ & $66.8 \%$ & $58.4 \%$ \\
\hline UTI & $11.4 \%$ & $13.6 \%$ & $8.5 \%$ & $9.6 \%$ & $20.8 \%$ & $8.1 \%$ & $20 \%$ \\
\hline Abdomen & $4.6 \%$ & $6.6 \%$ & $21 \%$ & $29 \%$ & $21.1 \%$ & $19 \%$ & $10 \%$ \\
\hline \multicolumn{8}{|l|}{ Meningo } \\
\hline encephalitis & $4.2 \%$ & & $2.1 \%$ & $2 \%$ & $1.6 \%$ & & $4.8 \%$ \\
\hline Soft tissue/ skin & $2.1 \%$ & $4.4 \%$ & $4.4 \%$ & $4.3 \%$ & $3.8 \%$ & $9.5 \%$ & \\
\hline \multicolumn{8}{|l|}{ Intra } \\
\hline vascular catheter & $7.4 \%$ & & $1.1 \%$ & $2.2 \%$ & $4.8 \%$ & & \\
\hline Infective endocarditis & $1.1 \%$ & & $.5 \%$ & & $1.1 \%$ & & \\
\hline Primary bacteremia & & & $2 \%$ & & & & \\
\hline \multicolumn{8}{|l|}{ Unknown/ } \\
\hline others & & & & & $12 \%$ & & \\
\hline
\end{tabular}




\section{Conclusion and recommendations:}

Our study describes presentation of severe sepsis in a medical ICU of tertiary care hospital of Bangladesh during a limited period's time. This study includes only adult medical patients.

The number of study population was small and limited to medical patients in the ICU of Bangladesh. This is the biggest limitation of our study.

Future study should involve much larger patient population \& different types of ICUs (e.g. surgical). Such study will help us to understand the dimension \& spectrum of severe sepsis in adult population of our country. This will also enable us to plan nationwide preventive and therapeutic strategy for such patient population.

\section{References :}

1. Dellinger RP, Levy MM, Carlet JM, Bion J, Parker MM, Jaeschke $\mathrm{R}$, etal.Surviving Sepsis Guidelines for management of Severe Sepsis and Septic Shock. Crit Care Med 2008; 36: 296-327.

2. Brun-Buisson C, Doyon F, Carlet J, et al; French ICU Group for Severe Sepsis. Incidence, risk factors, and outcome of severe sepsis and septic shock in adults: a multicenter prospective study in intensive care units. JAMA 1995; 274(12):968-74.

3. Guidet B, Aegerter P, Gauzit R, Meshaka P, Dreyfuss D. Incidence and impact of organ dysfunctions associated with sepsis. Chest $2005 ; 127(3): 942-51$

4. Angus DC, Linde-Zwirble WT, Lidicker J, Clermont G, Carcillo J, Pinsky MR. Epidemiology of severe sepsis in the United States: analysis of incidence, outcome, and associated costs of care. Crit Care Med 2001; 29(7):1303-10.
5. Engel C, Frank M, Brunkhorst, Bone HG, Brunkhorst R, Gerlach $\mathrm{H}$ et al. Epidemiology of sepsis in Germany: results from a national prospective multicenter study, Intensive Care Med2007; 33: 606-61

6. Greg, S., Martin, M., David M. Eaton S, Marc Moss.The Epidemiology of Sepsis in the United States from 1979 through 2000.New Engl J Med2003;348:1546-54

7. Derek C, Angus M, Walter T, Zwirble L, Lidicker J, Clermont G et al. Epidemiology of severe sepsis in the United States: Analysis of incidence, outcome, and associated costs of care. Crit Care Med2001; 29:1303-10.

8. Zanonl F, José J, Regina C, Michel S, Cabeda EV, Ceretta DF et al.Sepsis in the Intensive Care Unit: Etiologies, Prognostic Factors and Mortality.Crit Care Med 2008; 20(2): 345

9. Kauss MC, Grion Cardoso L T Q, Anami E H T,Nunes L B,Ferrira GL, Matsuo T, Bonametti A M. The epidemiology of sepsis in a Brazilian teaching hospital. Braz J Infect Dis2010;14(3):264-70

10. Phua J, Koh Y, Tang YQ, Divatia O, Tan C, Gomersall CD. Management of Severe Sepsis in patients admitted to Asian intensive care unit (MOSAICS).BMJ2011; 342:45

11. Ferrer R, Artigas A, Mitchell M. Levy, Jesu' s Blanco, Jose' Garnacho-Montero for the Edusepsis Study Group.Improvement in process of care and outcome after a multicenter severe sepsis educational program in spain.JAMA $2008 ; 299$ (19):2294-2303

12. Mitchell M, Levy M, Phillip Dellinger, Sean R. Townsend, Walter $\mathrm{T}$ et al. The Surviving Sepsis Campaign: Results of an international guideline based performance improvement program targeting severe sepsis.on behalf of the Surviving Sepsis Campaign. Crit Care Med2010; 38: 367-74

13. Faruq MO, Ahsan ASMA, Uddin MN, Khatun UHS, Mannan A, Tamanna RJ, et al. Implementation of Sepsis Bundles in Intensive Care Units of Bangladesh: A Prospective observational Study. Bangladesh Critical Care Journal 2013;1 (1): 8-17 